\title{
Application of e-Learning to Computer Science Teaching at Secondary Level
}

\author{
Maria Ijaz Baig ${ }^{*}$, Sameen Reza ${ }^{2}$ \\ 1,2 Virtual University of Pakistan, Pakistan. \\ * Corresponding author. email: Mariaijazbaig@hotmail.com \\ Manuscript submitted July 14, 2014; accepted August 30, 2014. \\ doi: $10.7763 /$ ijeeee.2014.V4.345
}

\begin{abstract}
Students have individual learning styles which cannot be catered to unless teachers also adapt different strategies to impart knowledge. To this end, delivery and assessment methods, which should be based on technology, are envisaged to be more effective. The aim of this study is to examine the effect of e-learning environment on the students' performance in the course of Computer Science applied at secondary level schools of Pakistan. The proposed study is conducted in local private school of Punjab. For this purpose, significant topics in the computer science course of 10th class are converted to an electronic format. This study is a quantitative study that applies Quasi Experiment, which has two groups (Control group and Treatment group), Pre-test and Post-test design model of testing. The cross-sectional time-horizon is most suitable for this study due to time constraint factor. Important results of this study are that students in e-learning group are considerably better in problem solving area and gained better practical knowledge of computer science as well. This study shows that e-learning has bright prospects in Pakistan. It can help the multifarious issues of secondary level education in Pakistan if it is applied in an appropriate manner.
\end{abstract}

Key words: E-learning, learning effectiveness, secondary level, computer science course.

\section{Introduction}

The advent of new technology is playing the role of catalyst between learning and teaching. E-learning is an electronic way of transferring lessons on digital devices. It has potential to increase the accessibility of quality education and supports the constructivist approach [1]. In order to cater to quality education, e-learning methodology accommodates three different learning styles i.e. visual learners, auditory learners and kinesthetic learners. It targets the individual learning preferences. It provides unprecedented control over the pace of learning content. In [2], author highlighted that secondary level education is the less cared area of education in Pakistan. The dropout rate at this level is high at almost $45 \%$. The reason of this high dropout is lack of quality education and stereotype learning where same pace of instruction is used for the whole class [3]. Traditional style teaching in Pakistan is facing various obstacle and challenges. Classes are overcrowded, students lose individual attention. Untrained teachers emphasize on reading the content rather than explaining with the help of visual aid. No assessment method is used to get instant response about the student's satisfaction about instruction. Only lecture style of study is followed which creates non-interest. Traditional secondary level style of teaching 
encourages the teacher-centered approach and students are passive listeners. It is known that students learn in many different ways. A single traditional method is not best for every learning need [4]. Researchers and analysts observe that students in e-learning environment showed greater improvement in practical ability, critical thinking, problem solving, academic achievement and time management as compared to students in traditional classroom environment. This article presents how effective is the e-learning environment in teaching Computer Science course at secondary level in Pakistan? Does it help to enhance student's learning skills more effectively and to what extend it satisfy them?

\section{Literature Review}

In [5], authors described the history of technology revolution. Since the introduction of computer and internet in the late 20th century; choices of flexible instructional and learning methods have been expanded. This expansion enabled the e-learning and various learning opportunities. E-learning has different forms for instance recorded lectures or by using different media features like graphical and textual representations. Therefore e-learning is a vast terminology that has various aspects concerning with the 'what', 'why' and 'how' of e-learning. What aspects include both content and instructional methodology. "Why" e-learning refers to the purpose of supporting personal learning objectives. "How" e-learning refers to how courses are delivered through computers or printed text. Therefore e-learning can be concluded as 'How courses are digitalized' 'what content it included' which helps individual to achieve the personal learning objectives [6]. In this last decade e-learning growth is dramatically increased which helps to manage different educational obstacles like shortage of experienced teachers and quality education [7]. MCQs based assessments are a boon for e-learning environment so it should not only design to assist memorization intention. It should be designed in such a way that it should also provide support in-depth understanding of subject content [8]. In St. Tammany Parish public school, Louisiana, an experiment was performed by applying e-learning and blended learning models on the core courses of English and World Geography. The main focus of this study was on effective use of technology to improve student's achievement. Results revealed that enforcing of these learning environments provided positive influences on student's achievement. Now school management is planning to teach English II and Civics with similar approach in their upcoming session. Henrico County Public Schools, Henrico, Virginia has used e-learning and blended learning environment in their physical education program. They reported these environments helped to satisfy all types of students [9].

According to reference [10], the ideal learning environment should be based upon:

- Multimedia incorporated learning

- Support the learner-centered environment

- Accommodates the different learning personalities of students

- Learning content should be accessible, anytime and anywhere

- Encourage activities with students that will help to quench their curiosity

E-learning transformed the educational system. It changes the thinking and practices by introducing new concepts that how students are taught and how they learn easily in addition to how digital resources can be utilized in education sector more efficiently [1]. The advantages of e-learning (Fig. 1) can be categorized as convenient; media rich, and consistent. It is convenient because learners can take control of the pace, and topics can be revisited whenever learners need to refresh. As choice of media is available it helps to deliver content in diverse and in more effective way. It also offers consistency by providing same quality of education for all. Using Learning Management Systems and other such tools, now students can assess their own progress. Other benefits of e-learning include that it is helping to increase the school enrollments. It is flexible (in terms of time, location mode etc) for those students who 
are unable to attend the conventional schools. It is affordable because of economy of scale; saves time and produce measurable results [11]. Through the use of media, learning content is easier to understand, more engaging and is able to accommodate multiple learning styles [12]. E-learning not only provides a connection of digital media and learning, it also accommodates student-centered approach. It helps to transform students from passive receivers to active seekers in the learning process [13].

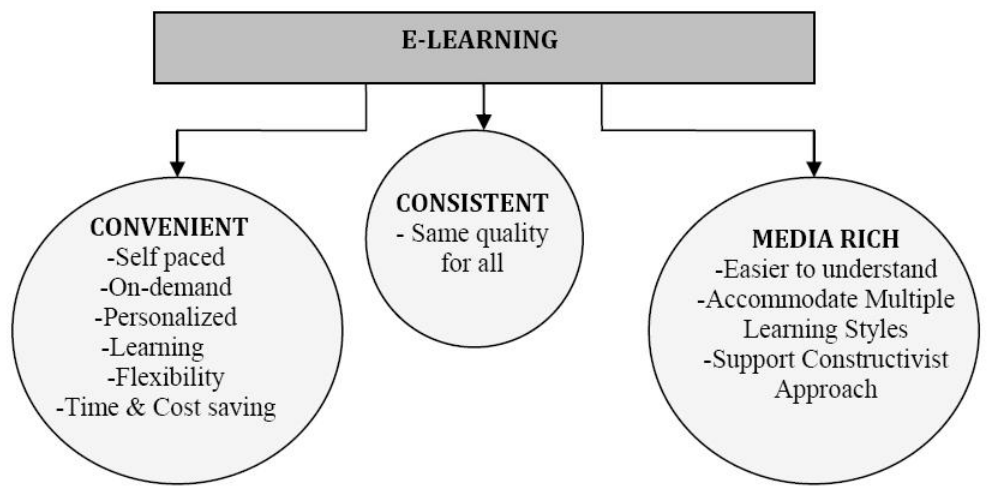

Fig. 1. Advantages of e-learning.

Among other the benefits of e-learning, learning content can also be easily loaded onto school computer labs, pen drives, and school servers etc., making it accessible everywhere. Videos of experiments, animated installments procedures, compiling and running programs can be easily demonstrated through the use of different software tools that help the students to visualize and retain knowledge more effectively [14].

Mostly e-learning have three modes of interactions namely Asynchronous (not real time), Synchronous (real time) and Blended Learning (e-learning and traditional). Synchronous e-learning includes technology such as virtual worlds, video conferencing etc. At the time of content delivery presence of students is required. Asynchronous (time-flexibility) e-learning include technology like prerecorded audio/video lectures, tutorials, online tests that permit students to work at their own time and pace. In 'asynchronous learning environment' the text material can either be used in electronic or may be in print form, web based assessment methods etc [5]. Almost 75\% existing courses available on internet are developed by using asynchronous learning environment [13]. Different students possessed different personality's traits, mind-sets, interaction and learning needs. Usually traditional classrooms support the "fast speed" which rewards to quick thinkers/vocals and applaud the extrovert learners. Introvert students sustain loss in these types of traditional learning environments. The asynchronous environments can provide an ideal space to introvert student which is needed for them to learn [15].

\section{Research Problem}

The purpose of this study is to identify secondary level student's capability in e-learning environment, by examining its use in the course of Computer Science. The computer science book published by Punjab Text Board for 10th class comprises on seven chapters and has $80 \%$ topics that are of practical nature. Students memorize the theoretical topics in a traditional class but it is commonly observed that they have no realistic view idea regarding functional aspects and problem solving area. Recent researches on e-learning have indicated positive results especially in practical nature courses. The above mentioned literature review caused us to surmise the hypotheses of this study.

\subsection{Hypotheses}


H1: Students in e-learning group are overall better academically.

H2: E-learning group is better at doing computer science practical.

H3: E-learning group gains more theoretical knowledge.

H4: E-learning group is better in problem solving area.

H5: E-learning has positive perception among students.

\section{Research Design}

The design of this study is descriptive in nature, it is a mono method quantitative and a cross sectional study. This implies the use of Quasi-experiment, pre-test and post-test design. Population of this experiment was students of 'Muhammadan Model High School' enrolled in the 10 population consisted of two sections, A and B. Arbitrarily the section 'A' formed the control group and section ' $\mathrm{B}$ ' formed an experimental group. Computer science book published by Punjab Text Board for $10^{\text {th }}$ was consulted for this study. The first chapter of this book was about problem solving methods cover theory based content. The next four chapters were based upon 'BASIC language' practical based initial level programming concepts. The sixth chapter is an introductory chapter about Computer Graphics (practical based). The seventh chapter is the lengthiest chapter of the book which covers all about practical working of Microsoft Word. Significant topics of this book, especially which are practical intensive and covered computer science problems were converted into a web based format. Computer science course classes were scheduled as four, 40 minutes lecture per week. Both sections (the control group and the treatment group) had classes on the same day.

Table 1. Research Design

\begin{tabular}{|c|c|c|c|c|}
\hline $\begin{array}{c}\text { Target } \\
\text { Population }\end{array}$ & Pre-Test & Treatment & Post-Test & Difference \\
\cline { 1 - 3 } $\begin{array}{c}\text { Experimental } \\
\text { Group }\end{array}$ & Y1 & $\begin{array}{c}\mathrm{X} \\
\text { (E-Learning) }\end{array}$ & Y2 & PreY-PostY \\
\hline Control Group & $\mathrm{Y} 1$ & $\begin{array}{c}\text { Traditional } \\
\text { Style } \\
\text { Leaming }\end{array}$ & Y2 & $\begin{array}{c}\downarrow \\
\text { Compare }\end{array}$ \\
\hline
\end{tabular}

Before the start of treatment same pre-test was conducted for both groups to examine their capability and differences related to the subject. After the analysis of pre-test results, students of the experiment group were introduced the videos, tutorials, online test website, self practicing and review exercises based on the provided e-content. For experiment group all MCQs based review exercises were loaded into test web site. MCQs were designed in a manner that covered all aspects imparted during lectures and provided context. Tutorials and lectures were developed by using internet resources. The complete process of working was practically performed in presence of individual student that how to listen to lectures, how to give online test, how to peruse tutorials and step by step problem solving methods etc. Control group were attended traditional classroom style lectures. After treatment same post-test was conducted in order to measure the learning difference between the both groups. The pre-test and post-test was developed to analyze the student's ability in doing practical work on the computer, competency in solving problems related to computer science and theoretical knowledge related to the subject.

The aim of this study was to analyze the hypotheses which would help to find out the 'cause' and 'effect' relationship between the variables. The independent variable is the application of e-learning to experiment group students. Dependent variable was the score of students in post test (Practical work Ability Score, Problem Solving Score and Theoretical Knowledge Score) and student's perception regarding e-learning. The 
pre-test and the post-test scores was analyzed with t-test by using excel. The pre-test was analyzed by the use of two tailed test and the post-test was evaluated by the use of one tailed test. The tool used to measure the perception of students regarding e-learning was questionnaire (1-5 Likert scale) filled in by the students at the end of the experiment.

\section{Results}

Before the start of this experiment, a questionnaire was given to students to investigate the use of computers in their daily life. The questionnaire results showed that students of experimental group had basic level familiarity with the use of computers and majority of them had access of internet in their homes as well in their school computer labs. Therefore un-usability will not have to be factored in the results of this study. (Table 2) presents the pre-test results which revealed that both groups initially possessed corresponding ability. The null hypothesis was accepted which indicated that both groups had the same background knowledge in ability to do practical work on the computer, problem solving skills and theoretical knowledge before the start of any treatment.

Table 2. Pre-Test Result Analysis

\begin{tabular}{|c|c|c|}
\hline Score Evaluation Categories & $\begin{array}{c}P(T<=t) \text { Two-tail } \\
\alpha=0.05\end{array}$ & Result \\
\hline 1. Practical Work Ability & 0.728 & $\begin{array}{l}\text { Accept the Null Hypothesis } \\
\qquad(p>0.05)\end{array}$ \\
\hline 2. Theoretical Knowledge & 0.599 & $\begin{array}{l}\text { Accept the Null Hypothesis } \\
\qquad(p>0.05)\end{array}$ \\
\hline 3. Problem Solving Skills & 0.602 & $\begin{array}{l}\text { Accept the Null Hypothesis } \\
\qquad(p>0.05)\end{array}$ \\
\hline 4. Total Score & 0.475 & $\begin{array}{l}\text { Accept the Null Hypothesis } \\
\qquad(p>0.05)\end{array}$ \\
\hline
\end{tabular}

Table 3. Post-Test Result Analysis

\begin{tabular}{|c|c|c|c|}
\hline Score Evaluation Categories & $\begin{array}{c}\boldsymbol{P}(\boldsymbol{T}<=\mathbf{t}) \text { one- tail } \\
\boldsymbol{\alpha}=\mathbf{0 . 0 5}\end{array}$ & Result & Conclusion \\
\hline \hline 1. Practical Work Ability & 0.000152 & $\begin{array}{c}P<0.05 \\
\text { Accepted }\end{array}$ & $\begin{array}{c}\text { Experiment group is } \\
\text { better at doing } \\
\text { computer science } \\
\text { practical. }\end{array}$ \\
\hline 2. Theoretical Knowledge & 0.190 & $\begin{array}{c}\text { In theoretical } \\
\text { Rejected }\end{array}$ & $\begin{array}{c}\text { knowledge there is no } \\
\text { considerable } \\
\text { difference among the } \\
\text { both groups. }\end{array}$ \\
\hline 3. Problem Solving Skills & 0.0109 & $\begin{array}{c}P<0.05 \\
\text { Accepted }\end{array}$ & $\begin{array}{c}\text { Experiment group is } \\
\text { significantly better in } \\
\text { problem solving area. }\end{array}$ \\
\hline 4. Total Score & 0.000737 & $\begin{array}{c}P<0.05 \\
\text { Accepted }\end{array}$ & $\begin{array}{c}\text { Students in e-learning } \\
\text { group are overall } \\
\text { better academically. }\end{array}$ \\
\hline 5. Students perception & & $\begin{array}{c}\text { Perception of } \\
\text { students regarding e- } \\
\text { learning was positive. }\end{array}$ \\
\hline
\end{tabular}

The post-test scores were again tabulated and one-tail t-test was applied to this data as shown by (Table 3). Results indicated that students in e-learning group were better in doing practical computer works and in 
problem solving skills than those studying in traditional classrooms. In these both categories null hypothesis was rejected in favor of alternate hypothesis. In theoretical knowledge scores null hypothesis was accepted which shows that there is no considerable difference in both groups.

At the end of this study post-Questionnaire was given to experiment group students to ascertain their perception regarding e-learning environment. Questionnaire was based on 10 questions (Appendix) inquiring them about overall experience of e-learning environment. In order to gauge student's perception Likert scale was used. 1 number was for strongly disagree and 5 for strongly agree. The descriptive Statistics analysis of students perception regarding e-learning were positive, $\mu \geq 3$. Results (Table 4) indicated their keen interest in the e-learning technology. Thus alternate hypothesis was accepted and null hypothesis was rejected.

Table 4. Descriptive Statistics of Student Perception

\begin{tabular}{|l|c|}
\hline \multicolumn{2}{|c|}{$\begin{array}{c}\text { E-learning Effectiveness } \\
\text { (Likert scale of 1 to 5) }\end{array}$} \\
\hline \hline Mean & 4.89 \\
\hline Standard Error & 0.0480 \\
\hline Median & 5 \\
\hline Mode & 5 \\
\hline Standard Deviation & 0.152 \\
\hline Sample Variance & 0.023 \\
\hline Range & 0.4 \\
\hline Minimum & 4.6 \\
\hline Maximum & 5 \\
\hline
\end{tabular}

\section{Observation and Discussions}

The above results (Table 3) indicate that students of experiment group show a better performance in problem solving skills, ability to do practical work on the computers as well as in overall scores as compared to control group. Post-test results exposed that in the field of theoretical knowledge both groups do not show a considerable difference. It has been analyzed during this study that e-learning methodology helped in enhancing the practical computer skills of experimental group. Students learned practical computer skills with the help of visual components very easily. Students of experiment group have more clear idea regarding functional aspects of Microsoft word, types of programming errors, saving of program etc. The main reason for this result seem to be interactive video lectures in which every computer based application were practically performed in a realistic mode. The principle of "learning by doing" was at the core of this study. For this purpose animation based exercises with clear instructions were provided to students through which they led gradually to solution of the given problem. It has been observed that e-learning students' problem solving skills were exceptionally enhanced. They had very strong idea what should be accomplished in each step and why. In one review exercise the problem logic was changed in this way that if students have strong idea they could solve it easily. The researcher of this thesis was surprised to note that all experimental group students solved it correctly. Most of the e-learning content delivered to students emphasized on developing their problem solving and computer based skills. Very less theory based content was delivered through this e-learning methodology. Therefore it seems rational that experimental group did very well in these fields in the post-test. Secondly, experimental group students attempted the review exercise based upon the content which they had listened in a video lecture. It has been seen that review exercises helped them to verify their own understandability after completion of the lecture. So after each lecture students were very much assured 
that which part was unclear for them and they asked very pertinent questions. Comparing with the control group, the treatment group was very much confident about what they had done so far and how to proceed further in a subject problem. Experimental group students were also unanimous in stating that the electronic based lectures had given them a profoundly realistic view of computer science subject and made study easier of them. E-lecture helped them in subsequent catch up of the lecture or part thereof that have found difficult to understand in a first attempt. After the accomplishment of this study student came with request to continue e-learning methodology in this course and teach them other sciences subjects like with this methodology. Their request was placed before the higher management which was not entertained due to lack of related facilities required for the asked subject.

\section{Conclusion and Recommendations}

E-learning approach to computer science teaching at secondary school level had not been researched earlier in Pakistan. In this respect the results of the conducted study were positive. E-learning environment effectively enhances the knowledge of students, improve their skills and motivate them to learn. Students in traditional classroom feel perturbed usually when they are asked to perform practical work. This study highlighted that e-learning qualify to enhance the students' practical prowess in doing computer work and ability to learn in a way that helps in problem solving. Therefore, secondary level schools should switch over to e-learning especially for the subjects that have practical aspects and require practice. Based upon this research, standard model can be developed to convert other secondary level science courses into e-learning. Moreover instructional medium should be designed considering learner's personality.

\section{References}

[1] Moore, M., \& Tait, A. (2002). Open and Distance Learning: Trends, Policy and Strategy Considerations. France: UNESCO.

[2] Aly, J. H. (2007). Education in Pakistan a White Paper (Revised): Document to Debate and Finalize the National Education Policy. Islamabad: National Education Policy Review Team Pakistan.

[3] Yang, A., \& Sato, Y. (2010). Secondary Education Regional Information: County Profile Pakistan. France: UNESCO.

[4] Norman, D. A., \& Spohrer, J. C. (1996). Learner-centered education. Communications of the ACM, 39(4), 24-27.

[5] Holden, J. T., \& Westfall, P. J. L. (2010). An Instructional Media Selection Guide for Distance Learning (6th ed.). Boston, MA: The United States Distance Learning Association.

[6] Clark, R. C., \& Mayer, R. E. (2008). E-learning and the Science of Instruction (2 ${ }^{\text {nd }}$ ed.). San Francisco: Jossey-Bass/Pfeifer.

[7] Clark, R. C., \& Mayer, R. E. (2011). E-Learning and the Science of Instruction: Proven Guidelines for Consumers and Designers of Multimedia Learning (3rd ed.). San Francisco: CA: Wiley \& Sons.

[8] Scalise, K., \& Gifford, B. (2006). Computer-based assessment in e-learning: A framework for constructing "intermediate constraint" questions and tasks for technology platforms. Journal of Technology, Learning and Assessment, 4(6), 1-2.

[9] Setzer, J. C., \& Lewis, L. (2005). Distance education courses for public elementary and secondary school students. Journal of Education Sciences, 7(2), 78-84.

[10] Schmitz, E., Prescott, C., \& Hunt, L. (1996). Learning Technology: The Effective Use of Technology in Education. New York: Center for Occupational Research and Development.

[11] Levy, J. (2005). Envision the future of e-learning. Canadian CIO, 13(2), 2-4. 
[12] Prensky, M. (2008). The Role of technology in teaching and the classroom. Educational Technology, 2(1), 1-3.

[13] Romiszowski, A. (2004). How's the e-learning baby: Factors leading to success or failure of an educational technology innovation. Journal of Educational Technology, 44(1), 4-21

[14] Chapman, D. W., \& Mahlck, L. 0. (2004). Adapting Technology for School Improvement: A Global Perspective. Paris: UNESCO International Institute for Educational Planning.

[15] Mupinga, D. M., Nora, R. T., \& Yaw, D. C. (2006). The learning styles, expectations, and needs of online students college teaching. College Teaching, 54(1), 185-189.

Maria Ijaz Baig received her MSCS degree from Virtual University, Pakistan. Her major interest areas are software engineering, and e-learning pedagogical strategies.

Sameen Reza received her MSCS degree from Virtual University, Pakistan. Her main interest areas are algorithms, theoretical computer science and technology assisted learning. She is currently working as an assistant professor at SZABIST Karachi, Pakistan. 